\title{
Sphincterotomy for anal fissure in Crohn's disease: is it dangerous?
}

\author{
Nicola Cracco $^{1} \cdot$ Roberto Zinicola $^{2}$
}

Accepted: 15 May 2015 / Published online: 24 May 2015

(C) Springer-Verlag Berlin Heidelberg 2015

\section{Dear Editor:}

Lateral internal sphincterotomy (LIS) for anal fissure (AF) in Crohn's disease (CD) has always been considered harmful. Most authors suggest that LIS should be reserved to carefully selected patients with persistent pain, without active rectal disease. We reviewed the literature in order to precise the real risk of complication after LIS for AF in CD patients. Only six retrospective studies including 48 patients were identified. The AF healing rate was $83 \%$. None experienced impairment of continence. Three patients complained of a not healed wound at the site of LIS. LIS was performed in unknown CD only in six out of 48 patients (12\%) [1]. The interval between surgery and occurrence of a complication was reported only in three studies and ranged from 4 months to 9 years (mean 16 months) [2-4]. A significative proportion of patients (19 out of 48 ) (40\%) suffered from postoperative complications. Of these patients, $40 \%$ underwent subsequent proctectomy. Interestingly, all patients without active rectal disease developed complications. This finding could suggest a cautious surgical approach even in selected "relatively safe" CD patients. Half of the studies did not precise the presence of active rectal disease, and none specified the anal disease status, particularly an abscess underlying the fissure. The interval time between LIS and complication onset ranged from few months to several years, arising the suspicion that the complication could be related to the progression of the disease rather than to surgery. It is well known that haemorrhoidectomy is much more harmful in unknown than known $\mathrm{CD}$ patients. We cannot confirm this issue also for LIS in AF, because only one small series reported surgery in unknown CD. Despite the high complication rate reported in our review, the small number of cases and the lack of detailed data do not allow to draw a firm conclusion on the danger of LIS for AF in CD patients.

\section{References}

1. D'Ugo S, Franceschilli L, Cadeddu F et al (2013) Medical and surgical treatment of haemorrhoids and anal fissure in Crohn's disease: a critical appraisal. BMC Gastroenterol 13:47

2. Wolkomir AF, Luchtefeld MA (1993) Surgery for symptomatic hemorrhoids and anal fissures in Crohn' disease. DCR 36:545-547

3. Vanheuverzwyn R, Detry R, Colin JF et al (1994) Chirurgie anale dans la maladie de Crohn. Ann Chirur 48:970-977

4. Fleshner PR, Schoetz DJ Jr, Roberts PL et al (1995) Anal fissure in Crohn's disease: a plea for aggressive management. DCR 38:11371143
Nicola Cracco

nicola.cracco@alice.it

1 Department of General Surgery, Sacro Cuore Don Calabria Hospital, Via Don A. Sempreboni 5, 37024 Negrar, Verona, Italy

2 Department of Emergency Surgery, Parma University Hospital, Via A. Gramsci 14, 43126 Parma, Italy 